\title{
O êxito no manejo clínico de um paciente com Trombocitopenia Neonatal Aloimune: estudo de caso
}

\author{
Successful clinical management of a patient with Aloimmune Neonatal Thrombocytopenia: \\ a case study
}
Manejo clínico exitoso de un paciente con Trombocitopenia Neonatal Aloinmune: un estudio de caso

Poliana Campos Melli ${ }^{1}$, Diego Miléo de Oliveira Freitas ${ }^{2 *}$.

\begin{abstract}
RESUMO
Objetivo: Demonstrar um estudo de caso de Trombocitopenia Neonatal Aloimune, doença onde anticorpos maternos anti-HPA1a penetram a barreira placentária e destroem as plaquetas fetais que possuem o antígeno HPA1a de origem paterna. Detalhamentos de caso: Recém-nascido do sexo masculino, por parto cesáreo de emergência devido Doença Hipertensiva Específica da Gestação (DHEG), pré-termo de 34 semanas, descendente de mãe jovem, caucasiana, primeira gestação e sem comorbidades autoimunes/imunológicas, evoluindo com hipoglicemia, dessaturação com cianose central e alteração na radiografia de tórax, demonstrando infiltrações bilaterais, com necessidade de suporte ventilatório invasivo e internação em Unidade de Terapia Intensiva Neonatal, devido forte suspeita de sepse, entretanto os resultados de exames demonstraram apenas plaquetopenia persistente, que apresentou melhora após teste diagnóstico com imunoglobulina humana e corticoesteroides. Considerações finais: Apesar de ser uma condição rara e considerada gravissima, neste presente caso a equipe obteve êxito no manejo clínico, apesar das condições técnicas laboratoriais da cidade não permitirem a realização de exames genéticos apurados.
\end{abstract}

Palavras-chave: Trombocitopenia, Aloimune, Recém-nascido.

\begin{abstract}
Objective: To demonstrate a case study of Aloimmune Neonatal Thrombocytopenia, a disease in which maternal anti-HPA1a antibodies penetrate the placental barrier and destroy fetal platelets that have the HPA1a antigen of paternal origin. Case details: Male newborn, by emergency cesarean delivery due to Pregnancy Specific Hypertensive Disease (PSHD), 34 weeks preterm, descendant of a young, Caucasian mother, first pregnancy and without autoimmune/immunological comorbidities, evolving with hypoglycemia, desaturation with central cyanosis and changes in the chest $X$-ray, showing bilateral infiltrations, requiring invasive ventilatory support and admission to the Neonatal Intensive Care Unit, due to a strong suspicion of sepsis, however the test results showed only persistent thrombocytopenia, which showed improvement after diagnostic test with human immunoglobulin and corticosteroids. Final considerations: Despite being a rare condition and considered very serious, in this case the team was successful in clinical management, despite the technical laboratory conditions in the city do not allow accurate genetic tests to be carried out.
\end{abstract}

Keywords: Thrombocytopenia, Alloimmune, Newborn.

${ }^{1}$ Hospital Samel, Manaus - AM.

2 Sociedade Brasileira de Clínica Médica (SBCM), Manaus - AM. *E-mail: d-m-o-f@hotmail.com

SUBMETIDO EM 4/2021

ACEITO EM: 5/2021

PUBLICADO EM: 6/2021 


\section{RESUMEN}

Objetivo: Demostrar un estudio de caso de Trombocitopenia Neonatal Aloinmune, una enfermedad en la que los anticuerpos maternos anti-HPA1a penetran la barrera placentaria y destruyen las plaquetas fetales que tienen el antígeno HPA1a de origen paterno. Detalles del caso: Recién nacido varón, por cesárea de urgencia por Enfermedad Hipertensiva Específica del Embarazo (EHEE), pretérmino de 34 semanas, descendiente de madre joven, caucásica, primer embarazo y sin comorbilidades autoinmunes / inmunológicas, evolucionando con hipoglucemia, desaturación con cianosis central y Alteración en la radiografía de tórax, mostrando infiltraciones bilaterales, con necesidad de soporte ventilatorio invasivo e ingreso a la Unidad de Cuidados Intensivos Neonatales, por fuerte sospecha de sepsis, sin embargo los resultados de la prueba solo mostraron trombocitopenia persistente, la cual mostró mejoría luego del diagnóstico. prueba con inmunoglobulina humana y corticosteroides. Consideraciones finales: A pesar de ser una condición poco común y considerada muy grave, en este caso el equipo tuvo éxito en la gestión clínica, a pesar de que las condiciones del laboratorio técnico de la ciudad no permiten realizar pruebas genéticas precisas.

Palabras clave: Trombocitopenia, Aloinmune, Recién nacido.

\section{INTRODUÇÃO}

A trombocitopenia ou plaquetopenia ocorre quando o valor plaquetário é inferior à 150 $109 / \mathrm{L}$ $\left(150.000 / \mathrm{mm}^{3}\right)$. Este componente sanguíneo é derivado da maturação dos megacariócitos, células de origem mielóide, que após formarem grânulos, organelas e ribossomos, os deslocam para suas extensões citoplasmáticas, desembocando nos vasos sinusoidais da medula óssea. Esta condição é causada por infecções, alterações genéticas, neoplasias e até casos de psudotrombocitopenia, causado principalmente, por erro laboratorial decorrente do uso do ácido etilenodiamino tetra-acético (EDTA) (CASTRO PF, 2016).

Neste escopo, temos a Trombocitopenia Neonatal Aloimune (TNA), a mais grave no recém-nascido, causada por anticorpos maternos que ultrapassam a barreira placentária, destruindo as plaquetas do concepto. Possui caráter genético e imunológico, relacionando-se ao polimorfismo do alelo rs6065, refletido como a presença treonina ou metionina na posição 161 da sub-unidade alfa da GPIb plaquetária, durante a mudança do nucleotídeo C1018T, implicando na produção de anticorpos maternos responsáveis por 75-90\% dos casos, em paciente caucasianas, o anti-HPA-1a (clase $\mathrm{lgG}$ ), direcionados a antígenos plaquetários de origem paterna como glicoproteínas Ilb/llla, Ib/IX, la/lla e CD 109. Nos asiáticos o antígeno HPA-4b é mais comum (KALMAN DA, et al., 2010; MOREIRA A, et al., 2011; MARQUES S, et al., 2017; PINA-CABRAL LB, et al., 2018).

Ocorre em 1/1500-1800 gestações, causando morte intrauterina, hemorragia intracraniana e sequelas neurológicas graves, nos sobreviventes. Esta estatítica é traduzida como 500 e 400 crianças por ano na Europa e nos Estados Unidos, respectivamente. A imunização materna contra o HPA1a fetal ocorre entre 8 a $24 \%$ das vezes na primeira gestação, principalmente se a mulher for positiva para o complexo de histocompatibilidade HLA-DRB3* $01: 01$, fato que aumenta de $12.7 \%$ a $25 \%$ as chances de produção de antiHPA1a. Entretanto, em $75 \%$ dos casos, imunização ocorre durante o parto, por contato com sangue fetal ou durante a gestação com exposição materna à beta-3 integrina das células placentárias do sinciotrofoblasto (KAJAER M, et al., 2020; SEQUEIRA Al, et al., 2020; VOS TW, et al., 2020).

A Trombocitopenia Neonatal Aloimune (TNA), deve ser lembrada em todos os recém-nascidos que apresentem plaquetas abaixo de $50 \times 10^{9} / \mathrm{L}\left(50.000 / \mathrm{mm}^{3}\right)$, petéquias, púrpura, anemia, hemorragias graves, principalmente intracraniana, na ausência de sepse, $\mathrm{TORCH}$, síndrome da ausência do osso rádio, síndrome da falência medular congênita, trombose de veia renal, somado à mãe sem doença autoimune e plaquetas normais (KALMAN DA, et al., 2010; MOREIRA A, et al., 2011; CONTI FM, et al., 2014).

Dessa forma, este estudo tem por objetivo demonstrar um caso de Trombocitopenia Neonatal Aloimune e o tema se justifica devido a esta doença poder estar presente em nosso meio, sendo subdiagnosticada, seja por falta de instrumental técnico, inexperiência dos serviços pediátricos ou pelo ônus financeiro que alguns exames demandam, principalmente os de especificação genética. 


\section{DETALHAMENTO DO CASO}

Os dados contidos neste artigo foram retirados dos prontuários médicos da mãe e do recém-nascido, após assinatura do Termo de Consentimento Livre e Esclarecido (TCLE) pela mesma, baseado na Resolução 466/2012 do Conselho Nacional de Saúde (CNS) e aprovado pela instituição onde ocorreu o atendimento médico, configurando trabalho para fins acadêmicos, onde os pacientes não receberam nenhum benefício financeiro e nem tiveram despesas, suas identidades estão mantidas em sigilo e possuem total acesso aos dados da publicação.

O paciente nasceu em uma cidade do estado do Amazonas, identificado como recém-nascido de A.C.F, no dia 19 de Fevereiro de 2020 às 01:22h, devido emergência obstétrica, no caso, Doença Hipertensiva Específica da Gestação (DHEG), realizado parto cesáreo, sem intercorrências. Na sala de parto foram caracterizados os seguintes parâmetros: sexo masculino, idade gestacional de 34 semanas (pré-termo) e Adequado para Idade Gestacional (AIG), peso 1.970g, Apgar 1 minuto 7 e 5 minutos 9, apresentação cefálica, líquido meconial fluido.

$\mathrm{Na}$ avaliação inicial da neonatologia, recém-nascido não chorou ao nascer, frequência cardíaca acima de 100 batimentos por minuto, apresentou flexão de extremidas, cianose com necessidade de aspiração e dois ciclos de ventilação com pressão positiva iniciada com bolsa-válvula-máscara mais reservatório de oxigênio. Permaneceu em observação no Alojamento Conjunto (ALCON) com a mãe devido dispnéia leve residual, evoluindo com melhora e apresentando sucção moderada ao dedo de luva. Foi realizado credeização ocular com nitrato de prata $1 \%$ e vitamina $\mathrm{K}$ intramuscular.

Mesmo após medidas iniciais de estabilização, paciente evoluiu com dessaturação, chegando a SatO2 85\% (oxímetro de pulso) embora estivesse em Bl-level Positive Airway Pressure (BIPAP), piora da cianose, além de hipoglicemia (glicemia capilar abaixo de $40 \mathrm{mg} / \mathrm{dl}$ ). Ao exame físico estava hipoativo, dispnéico moderado, anictérico, afebril ao toque, desidratado, corado, sem edemas e com fontanelas normotensas. Ausculta cardíaca com ritmo cardíaco regular, dois tempos, bulhas normofonéticas, sem sopros e ausculta pulmonar com murmúrio vesicular fisiológico sem ruídos adventícios, abdome plano, flácido, sem visceromegalias e ruídos hidroaéreos presentes.

Dessa forma, foram tomadas medidas mais agressivas de suporte com passagem de sonda nasogástrica, cateterismo venoso umbilical, glicose hipertônica, hidratação venosa e reposição de eletrólitos, além de coleta de hemocultura, gasometria arterial e radiografia de tórax, com solicitação de internação em Unidade de Terapia Intensiva Neonatal (UTI Neo).

Às $11 \mathrm{~h}$ do dia 19/02/20, paciente foi intubado e colocado em ventilação mecânica. Os exames da admissão da UTI Neo, apresentaram os seguintes resultados: tipagem sanguínea $A+$, sorologias (VDRL não reagente, Toxoplasmose não reagente, HIV I e II não reagente, hepatite $B$ não reagente), cloro $87 \mathrm{mEq} / \mathrm{L}$, fósforo 3.1 $\mathrm{mg} / \mathrm{dL}$, magnésio $1.4 \mathrm{mg} / \mathrm{dL}$, potássio $3.7 \mathrm{mEq} / \mathrm{L}$, proteína $\mathrm{C}$ reativa $2.5 \mathrm{mg} / \mathrm{L}$, $\mathrm{Na} 123 \mathrm{mEq} / \mathrm{L}$, primeiro hemograma (hemoglobina $17.7 \mathrm{~g} / \mathrm{dL}$, hematócrito $52.7 \%$, leucograma $10.090 \mathrm{~mm}^{3}-51 \%$ de segmentados e $45 \%$ de linfócitos, plaquetas $52.000 \mathrm{~mm}^{3}$ ).

A radiografia de tórax demonstrava pulmões hipotransparentes bilateralmente, sendo interrogado Doença da Membrana Hialina e Síndrome da Aspiração Meconial, realizado surfactante na dose de $2.5 \mathrm{mg} / \mathrm{kg}$ e ajuste dos parâmetros ventilátorios, com melhora da saturação significativa e radiológica, com nova radiografia após $6 \mathrm{~h}$ de intubação. Aventada possibilidade de infecção aguda, levando em consideração o quadro clínico inicial, além da plaquetopenia, foi iniciada antibióticoterapia com gentamicina mais ampicilina, que perdurou do dia 20/02-27/02, quando esquema foi suspenso, e mantido apenas cefepime (28/02-02/03). O paciente permaneceu em ventilação mecânica por 48h (extubação 21/02, sem intercorrências), após melhora clínica e radiológica.

Como demonstrado na Tabela 1, paciente evoluiu com piora da plaquetopenia, apesar da provável sepse estar sob controle, o que levou a equipe a rever o prontuário materno, inferindo possível doença autoimune. Ao avaliarmos os hemogramas da genitora, observamos os seguintes valores $\left(\mathrm{mil}^{2} / \mathrm{mm}^{3}\right): 01 / 11 / 2019177.000$, 13/01/2020 178.000, 19/02/2020 105.000, 22/02/2020 111.000. Dessa forma, foi optado por realizar teste 
diagnóstico com metilprednisolona $1 \mathrm{mg}$ de 8/8h endovenoso por três dias (28-29/02 e 01/03) e Imunoglobulina Humana IgG 2.110g nos dias 28-29/02, com elevação plaquetária significativa.

Tabela 1 - Resultados de Hemograma, Eletrólitos e Prova Inflamatória (PCR).

\begin{tabular}{|c|c|c|c|c|c|c|}
\hline \multirow{2}{*}{ EXAME } & \multicolumn{6}{|c|}{ DATA } \\
\hline & 20/FEV & 21/FEV & 25/FEV & 27/FEV & 02/MAR & 10/MAR \\
\hline $\begin{array}{l}\mathrm{Hb}(\mathrm{g} / \mathrm{dL}) \\
\mathrm{VL} 13.5-19.6\end{array}$ & 17.8 & 19.3 & 21.4 & 19.1 & 18 & 16.2 \\
\hline $\begin{array}{l}\mathrm{Ht}(\%) \\
\text { VL } 44-62 \%\end{array}$ & 52.4 & 58.7 & 60.8 & 54.5 & 52.4 & 47.3 \\
\hline $\begin{array}{l}\text { Leucócitos Totais }\left(\mathrm{mm}^{3}\right) \\
\text { VL } 4000-10000\end{array}$ & 5.990 & 5.540 & 4.390 & 4.520 & 5.360 & 5.030 \\
\hline $\begin{array}{l}\text { Plaquetas }\left(\mathrm{mm}^{3}\right) \\
\text { VL } 150.000-450.000\end{array}$ & 49.000 & 37.000 & 22.000 & 14.000 & 116.000 & 374.000 \\
\hline $\begin{array}{l}\mathrm{Na}(\mathrm{mEq} / \mathrm{L}) \\
\mathrm{VL} 137-145\end{array}$ & 123 & 127 & 131 & 137 & - & - \\
\hline $\begin{array}{l}\mathrm{Ca}(\mathrm{mg} / \mathrm{dL}) \\
\mathrm{VL} 8.4-10.2\end{array}$ & 8.1 & 8.5 & 9.9 & 9 & - & - \\
\hline $\begin{array}{l}\mathrm{K}(\mathrm{mEq} / \mathrm{l}) \\
\mathrm{VL} 3.5-51\end{array}$ & 3.7 & 2.9 & 4.5 & 4.3 & - & - \\
\hline $\begin{array}{l}\text { Fósforo }(\mathrm{mg} / \mathrm{dL}) \\
\text { VL } 2.5-4.5\end{array}$ & 3.1 & 2.6 & 2.5 & 3.5 & - & - \\
\hline $\begin{array}{l}\mathrm{Mg}(\mathrm{mg} / \mathrm{dL}) \\
\mathrm{VL} 1.6-2.3\end{array}$ & 1.4 & 1.6 & 2.1 & 1.9 & - & - \\
\hline $\begin{array}{l}\text { PCR (mg/L) } \\
\text { VL: }>6 \mathrm{mg} / \mathrm{dL} \text { positivo } \\
<6 \mathrm{mg} / \mathrm{dL} \text { negativo }\end{array}$ & 2.5 & 2.3 & 1.9 & 0.6 & - & - \\
\hline
\end{tabular}

Legenda: $\mathrm{Hb}$ - hemoglobina, Ht - hematócrito, $\mathrm{Na}$ - sódio, $\mathrm{Ca}$ - cálcio, $\mathrm{K}$ - potássio, P - fósforo, Mg - magnésio, PCR - proteína C reativa, VL - valor de referência. Fonte: Melli PC e Freitas DMO, 2021.

De acordo com o Quadro 1, as sorologias não demonstraram nenhuma infecção do grupo TORCH. As hemoculturas foram negativas, nenhuma outra síndrome aparente ou uso de medicamentos que alterem a função plaquetária pela mãe foram detectados, e o recém-nascido também não apresentou nenhum tipo de hemorragia, nem a clássica hemorragia intracraniana presente nesta patologia, comprovado pelo ultrassom transfontanela realizado dia 01/03.

Quadro 1 - Sorologias coletadas dia 02/03/2020 para grupo TORCH.

\begin{tabular}{|c|c|c|}
\hline Exame & Resultado & Referência \\
\hline VDRL & Soro não reagente & Soro reagente/ não reagente \\
\hline HIV I e II & Soro não reagente & Soro reagente/ não reagente \\
\hline Herpesvírus Simples I e II lgG & Índice 30 & $\begin{array}{l}\text { Não reagente: Inferior a } 0.9 \\
\text { Indeterminado: Acima } 0.9 \text { e abaixo de } 1.1 \\
\text { Reagente: Superior a } 1.1\end{array}$ \\
\hline Herpesvírus Simples I e II lgM & Índice 0.5 & $\begin{array}{l}\text { Não reagente: Inferior a } 0.9 \\
\text { Indeterminado: Acima } 0.9 \text { e abaixo de } 1.1 \\
\text { Reagente: Superior a } 1.1\end{array}$ \\
\hline Parvovírus B19 lgG & $63.60 \mathrm{UI} / \mathrm{ml}$ & $\begin{array}{l}\text { Não reagente: Inferior a } 4 \mathrm{Ul} / \mathrm{ml} \\
\text { Indeterminado: } 4 \text { a } 5 \mathrm{UI} / \mathrm{ml} \\
\text { Reagente: Superior a } 5.5 \mathrm{Ul} / \mathrm{ml}\end{array}$ \\
\hline Parvovírus B19 lgM & $0.18 \mathrm{Ul} / \mathrm{ml}$ & $\begin{array}{l}\text { Não reagente: inferior a } 10 \mathrm{Ul} / \mathrm{ml} \\
\text { Indeterminado: } 10 \text { a } 15 \mathrm{Ul} / \mathrm{ml} \\
\text { Reagente: Superior a } 5.5 \mathrm{Ul} / \mathrm{ml}\end{array}$ \\
\hline Rubéola - Teste de Avidez lgG & $70 \%$ & $\begin{array}{l}\text { Baixa avidez: Inferior a 35\% - infecção primária } \\
\text { aguda } \\
\text { Avidez intermediária: } 35 \%-45 \% \text { - infecção } \\
\text { primária durante as últimas } 6 \text { semanas } \\
\text { Avidez Alta: acima } 45 \% \text {. Exclui infecção primária } \\
\text { nas últimas } 6 \text { semanas }\end{array}$ \\
\hline
\end{tabular}

Fonte: Melli PC e Freitas DMO, 2021. 
O teste do coraçãozinho, olhinho e triagem auditivas normais. Teste do Pezinho (02/03), demonstrou fenilalanina, TSH e galactose elevadas, mas sem repercussões. Realizamos transfusão de uma unidade de plaquetas no dia 28/02 devido valor sério estar em 14 mil. Foi solicitado genotipagem do paciente e dos pais para HPA1a. O paciente evolui bem e segue está sendo monitorado pelo setor ambulatorial.

Figura 1 - Fluxograma de Atendimento em Suspeita de Trombocitopenia Neonatal Aloimune.

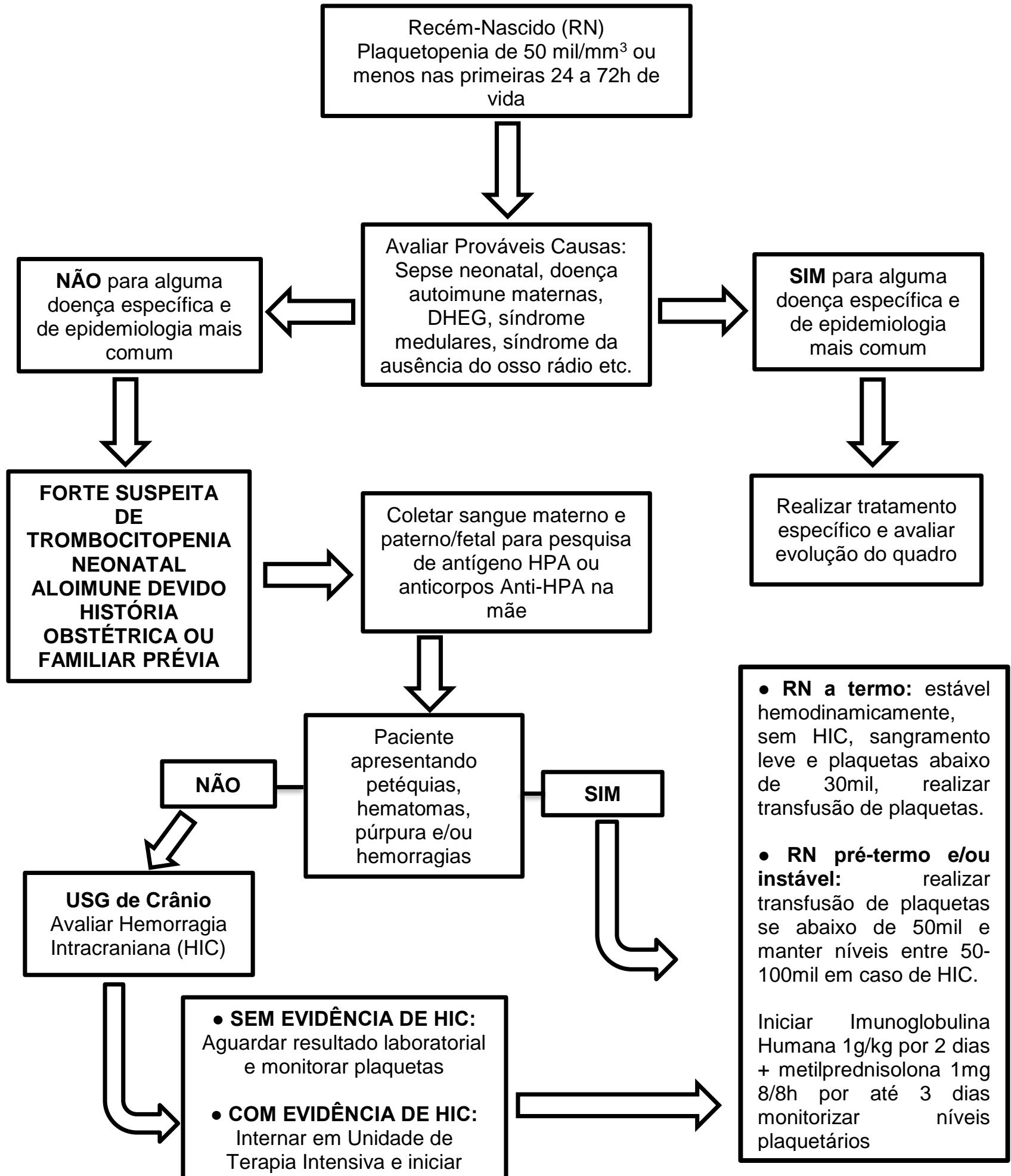

Fonte: Melli PC e Freitas DMO, 2021; baseada nos trabalhos de Montenegro CA, et al., 2018 e Sequeira Al, et al., 2020. 


\section{DISCUSSÃO}

Segundo o American College of Obstetricians and Gynecologists (ACOG) (2016) as principais causas de trombocitopenia gestacionais são: hipertensão (pré-eclâmpsia e síndrome HELLP), trombocitopenia imune primária e secundária (síndrome do anticorpo antifosfolipidio, lúpus eritematoso sistêmico, infecções virais e induzidas por drogas), associadas com condições sistêmicas (coagulação intravascular disseminada, púrpura trombocitopênica trombótica, síndrome hemolítico-urêmica, púrpura trombocitopência idiopática, sequestro esplênico, desordens medulares) e trombocitopenia congênita.

A trombocitopenia neonatal aloimune caracteriza-se por incompatibilidade entre o HPA materno e paterno/fetal, além da detecção de anticorpos anti-HPA-1a no sangue da mãe, afetando 1 recém-nascido entre 1000-3000, ocorrendo muitas vezes já na primeira gestação, acarretando Hemorragia Intracraniana $\mathrm{HIC)}$ grave, geralmente intrauterino que ocorre até a $28^{\mathrm{a}}$ semana gestacional em $80 \%$ dos registros. A maioria dos casos, ocorre em mulheres saudáveis, sem doenças autoimunes prévias, com níveis plaquetários normais e gravidez considerada de baixo risco, de origem caucasiana, onde estima-se que apenas $2 \%$ desta população é HPA1a-negativa (KAMPHUIS MM, et al., 2016; MONTENEGRO CA, et al., 2018; SEQUEIRA AI, et al., 2020).

Ao avaliar-se um caso suspeito, na presença de incompatibilidade materno-fetal HPA1a e na ausência de anticorpos anti-HPA1a maternos, deve-se repetir a sorologia entre 2 e 4 semanas. O diagnóstico preciso é fundamental na primeira gestação, não apenas pelo início do tratamento precoce do recém-nascido, como irá melhorar a triagem desta mãe nas próximas concepções, onde tende a ser pior. A pesquisa do genótipo HPA paterno também é importante, pois se o mesmo for homozigoto (HPA-1a/1a), todos os fetos originados serão incompatíveis e estarão em risco. Nos países desenvolvidos e com melhores avanços na área médica a aloimunização é testada através do DNA fetal livre no plasma materno e dosagem do anticorpo anti-HPA1a endotelial específico, subtipo anti- $\alpha$ V $\beta 3$ (WINKELHORST D, et al., 2017).

Os estudos sobre o tema são categóricos ao estabelecer o ponto fundamental do tratamento, seja ele em caso primário ou em gestação subsequente, não é evitar a trombocitopenia e sim, as complicações hemorrágicas, principalmente a $\mathrm{HIC}$, detectada em $52 \%$ das vezes com ultrassonografia seriada, considerada método inicial de triagem, uma vez que, a única maneira de se detectar o nível plaquetário do feto é através da cordocentese, procedimento de alto risco, apresentando $8 \%$ de complicações (WINKELHORST D, et al., 2017; MONTENEGRO CA, et al., 2018; VOS TW, et al., 2020).

Estabelecido o diagnóstico ou suspeita da doença intra-útero, a imunoglobulina humana endovenosa, utilizada pela primeira vez por Bussel JB, et al. (1988), deve ser iniciada, pois em diversos estudos apresentou eficácia de $97.3 \%$ a $98.7 \%$ na prevenção da HIC, embora seu mecanismo de ação ainda não esteja elucidado. A idade gestacional para início da imunoglobulina varia conforme o país de estudo entre 20 a 28 semanas, exceto se a mulher já apresentou feto com HIC na gestação anterior, iniciando na $16^{\text {a }}$ semana (WINKELHORST D, et al., 2017; MONTENEGRO CA, et al., 2018; VOS TW, et al., 2020).

Os corticoesteróides são utilizados tanto no período pré-natal quanto no pós-natal, associados à transfusão de plaquetas e à imunoglobulina, porém seu valor de evidência é fraco. Inicialmente foi utilizada dexametasona na dose de $3-5 \mathrm{mg} / \mathrm{kg}$ mais imunoglobulina, no tratamento antenatal, porém devido efeitos colaterais como oligodrâmnio e tempo de ação curto, foi substituída pela prednisona $0.5 \mathrm{mg} / \mathrm{kg} / \mathrm{dia}$. Winkelhorst D, et al. (2017) avaliou 11 estudos que realizaram tratamento de imunoglobulina associado ou não a corticoesteróides e apenas 1 demonstrou aumento plaquetário, portanto estas medicações não são indicadas como primeira linha e nem em uso isolado na TNA (LIEBERMAN L, et al., 2019; VOS TW, et al., 2020).

Quanto à via de parto, cesárea está mais indicada, principalmente na ausência da contagem plaquetária pré-natal, pois minimiza sangramentos e possíveis traumas. Entretanto, o parto vaginal não apresenta contraindicação absoluta, desde que a contagem de plaquetas do recém-nascido esteja entre 50.000 e $100.000 / \mathrm{mm}^{3}$, mãe não tenha gravidez prévia com HIC e seja evitado qualquer instrumento traumático como fórceps (CONTI FM, et al., 2014; WINKELHORST D, et al., 2017). 
Na Noruega, país com melhores estudos sobre o tema, mulheres com elevados níveis de anti-HPA1a (maior ou igual a $3 \mathrm{Ul} / \mathrm{ml}$ ) são selecionadas para cesárea eletiva por volta de 38-39 semanas em casos de primeira gestação e 37 semanas se, na gravidez anterior, houve hemorragia intracraniana. A contagem plaquetária é realizada por coleta do sangue do cordão umbilical e a transfusão realizada, se necessária, em até 30 minutos após o nascimento (TILLER H, et al., 2020).

O recém-nascido que apresentar forte suspeita de trombocitopenia neonatal aloimune será conduzido conforme fluxograma da Figura 1, realizado na maioria dos estudos pesquisados. Apesar da transfusão de plaquetas diminuir o risco de sangramento entre 20 a 30\%, a mortalidade não está relacionada à trombocitopenia diretamente, mas é proporcional ao número de transfusões (RESCH E, et al., 2018).

Em emergências indica-se o uso de plaquetas randomizadas, porém o uso de componentes lavados, filtrados e irradiados está mais indicado porque diminuem o risco de doença do enxerto-versus-hospedeiro pós-transfusional. Plaquetas maternas podem ser isoladas com antecedência e doadores HPA-1b1b por aférese devem ser contatados para doar próximo à data provável do parto. Devemos ser cautelosos, pois as particularidades e maturidade da fisiologia pediátricas colocam esta população em maior risco para eventos adversos, principalmente relacionados a antígenos HLA de plaquetas e linfócitos (CONTI FM, et al., 2014; AMARAL VH, et al., 2019; SEQUEIRA Al, et al., 2020).

Pode-se comparar esse caso com os dados disponíveis na literatura, pois a mãe possui descendência caucasiana, é jovem (36 anos), sem comorbidades reumatológicas/autoimunes, porém apresentava hipertensão (DHEG) desde as 27 semanas, sendo sua primeira gestação, até o momento do parto não apresentou nenhuma complicação ou relatou quadro infeccioso (MOREIRA A, et al., 2011; CONTI FM, et al., 2014; WINKELHORST D, et al., 2017; MONTENEGRO CA, et al., 2018; TEIXEIRA AT, et al., 2018; SEQUEIRA Al, et al., 2020).

O parto foi emergencial e de 34 semanas, um feto, sexo masculino, aparentemente normal, sem deformidades e sinais de sangramento, porém apresentando plaquetopenia não relacionada a demais patologias, que alcançou níveis normais após uso de imunoglobulina humana e corticoide, internado em unidade de terapia intensiva, ao apresentar hipoglicemia, cianose e hipotonia com dessaturação, sendo interrogado sepse, configurando o perfil de manifestação da doença encontrado nos estudos utilizados como referência (MOREIRA A, et al., 2011; CONTI FM, et al., 2014; WINKELHORST D, et al., 2017; MONTENEGRO CA, et al., 2018; TEIXEIRA AT, et al., 2018; SEQUEIRA Al, et al., 2020).

Quanto à questão do tratamento instaurado, procedeu-se conforme protocolo da Figura 1, foi solicitada coleta de sangue do RN e dos pais para pesquisa de anticorpos e genótipo, entretanto, na cidade estudada, não dispõe-se de laboratórios tecnicamente capacitados para realização de exames genéticos, soma-se a isso os planos de saúde que não possuem cobrirem exames deste tipo, fazendo com que os usuários arquem com os custos para realização, o que aconteceu com a família do caso, que conseguiu pagar apenas a fenotipagem plaquetária da criança (MONTENEGRO CA, et al., 2018; SEQUEIRA Al, et al., 2020).

Outra dificuldade encontrada é o fato da família morar no interior do estado do Amazonas, cujo meio de acesso é somente por barcos e/ou avião, o que prejudica o acompanhamento posterior do caso. Contactouse a mãe após a alta hospitalar, e a mesma relatou não conseguir retornar à capital para reaver o resultado do exame e que até o presente momento a criança se desenvolve normalmente (MONTENEGRO CA, et al., 2018; SEQUEIRA AI, et al., 2020).

A Trombocitopenia Neonatal Aloimune, embora rara e grave, é uma doença que alcança bons resultados quando o tratamento é instaurado de forma rápida e precoce, principalmente nas gestações subsequentes de casos previamente conhecidos. Os hospitais que possuem serviços de neonatologia/pediatria e obstetrícia precisam de laboratórios com qualidade técnica para realizar exames genéticos e banco de sangue com plaquetas tratadas e genotipadas, para transfusões emergenciais. O diagnóstico preciso é fundamental na prevenção da hemorragia intracraniana assim como 0 monitoramento dos níveis plaquetários e desenvolvimento desta criança ambulatorialmente. É necessário orientar os pais e acompanhar as próximas gestações para evitar as complicações da doença. 


\section{REFERÊNCIAS}

1. AMERICAN COLLEGE OF OBSTETRICIANS AND GYNECOLOGISTS. ACOG Practice Bulletin 166. Obstet Gynecol, 2016; 128(3): e43-53.

2. AMARAL VH, SANTOS MC. Avaliação da adequação do uso de hemocomponentes em pacientes pediátricos não críticos. Residência Pediátrica, 2019; 9(2): 125-131.

3. BUSSEL JB, et al. Antenatal treatment of neonatal alloimmune thrombocytopenia. N Engl J Med, 1988; 319: 1374-78.

4. CASTRO PF. Trombocitopenias e avaliação de pseudotrombocitopenias - casos clínicos. Dissertação (Mestrado em Análises Clínicas) - Faculdade de Farmácia. Universidade do Porto, Porto, 2016; 147 p.

5. CONTI FM, et al. Sucesso no manejo da trombocitopenia aloimune neonatal na segunda gestação: relato de caso. Einstein, 2014; 12(1): 96-9.

6. KAJAER M, et al. Strategies to develop a prophylaxis for the prevention of HPA-1 ${ }^{\text {a }}$ immunization and fetal and neonatal alloimmune thrombocytopenia. Transfur Apher Sci, 2020; 59(1) 102712: 1-6.

7. KALMAN DA, et al. Plaquetopenia neonatal aloimune: apresentação de doiscasos clínicos com revisão da literatura. Rev Med (São Paulo), 2010; 89(2): 88-92.

8. KAMPHUIS MM, et al. Fetal and Neonatal Alloimmune Thrombocytopenia: management and outcome of a large international retrospective cohort. Fetal Diagn Ther, 2017; 41(4): 251-57.

9. LIEBERMAN L, et al. Fetal and neonatal alloimmune thrombocytopenia: recommendations for evidence-based practice, an international approach. British Journal of Haematology, 2019; 185: 549-562.

10. MARQUES S, et al. Um Caso de Trombocitopenia Neonatal com Neutropenia. Gazeta Médica. 2017; 4(4): 228-30.

11. MONTENEGRO CA, et al. Trombocitopenia na gravidez. Femina®, 2018; 46(3): 190-6.

12. MOREIRA A, et al. Trombocitopenia severa neonatal. Nascer e Crescer: Revista do Hospital de Crianças Maria Pia, $2011 ; 20(1): 20-2$.

13. PINA-CABRAL LB, et al. Myocardial infarction before and after the age of 45: possible role of platelet receptor polymorphisms. Rev Port Cardiol., 2018; 37(9): 727-735.

14. RESCH E. Neonatal thrombocytopenia: causes and outcomes following platelet transfusions. Eur J Pediatr., 2018; 177(7): 1045-52.

15. SEQUEIRA Al, et al. Immune neonatal thrombocytopenia - review. Birth and Growth Medical Journal, 2020; 29(1): 2935.

16. TEIXEIRA AT, et al. Trombocitopenia Neonatal Aloimune: um diagnóstico a ter em mente. Acta Pediatr Port, 2018; 49 : 193-6.

17. TILLER $\mathrm{H}$, et al. Fetal and neonatal alloimmune thrombocytopenia - The Norwegian management model. Transfusion and Apheresis Science, 2020; 59(102711): 1-5.

18. VOS TW, et al. Epidemiology and management of fetal and neonatal alloimmune thrombocytopenia. Transfur Apher Sci., 2020; 59(1) 102704: 1-8.

19. WINKELHORST D, et al. Antenatal management in fetal and neonatal alloimmune thrombocytopenia: a systematic review. BLOOD, 2017; 129(11): 1538-47.

20. WINKELHORST D, et al. Fetal and neonatal alloimmune thrombocytopenia: evidence based antenatal and postnatal management strategies. Expert review of hematology, 2017; 10(8): 729-737. 